${ }^{49}$ Не опубликовано. См.: Справочная правовая система ГАРАНТ. Версия 4.07.

50 Пункт 4 "Положения о Международном коммерческом арбитражном суде при Торгово-промышленной палате Российской Федерации”, являющегося приложением 1 к Закону РФ "О международном коммерческом арбитраже".

${ }^{51}$ Не опубликован. См.: Справочная правовая система ГАРАНТ. Версия 4.07.

52 Howard M. Holtzmann, Joseph E. Neuhaus A Guide To the UNCITRAL Model Law on International Commercial Arbitration. Legislative History and Commentary. Deventer, Boston, The Hague, 1994.

53 Подробнее см.: Муранов А.И. Проблема определения суда, компетентного рассматривать вопрос о приведении в исполнение в Российской Федерации иностранных решений по коммерческим спорам. - Московский журнал международного права, 2000, № 1.

Статья поступила в редакцию в октябре 1999 года.

\title{
ОГОВОРКА О ПУБЛИЧНОМ ПОРЯДКЕ: ПРИМЕНЕНИЕ В МЕХДУНАРОДНОМ КОММЕРЧЕСКОМ АРБИТРАЖЕ
}

\author{
Н.В. П р и е 3 жа я*
}

Автономию воли сторон при выборе применимого права в процессе разрешения спора в значительной мере ограничивает принцип, согласно которому применение закона, выбранного сторонами, не может нарушать публичный порядок страны, где это применение должно осуществляться. Публичный порядок, связанный с местом арбитражного разбирательства или с местом исполнения решения, является тем пределом применимости иностранного закона, выбранного сторонами, который признается всеми правовыми системами.

Охрана основ всеми признанного устройства, мирового порядка и общественной морали свойственна как любому государству в отдельности, так и региональным и международному сообществам в целом. Статья 6 французского гражданского кодекса гласит, что “нельзя нарушать частными соглашениями общественный порядок и добрые нравы". 1

Под публичным порядком понимается соблюдение государственных интересов. В широком смысле слова публичный порядок можно приравнять к законодательной политике, и, следовательно, под противоречием общественному порядку понимается все, что относится к противоправной деятельности, ограничению свободы, коммерческой деятельности и естественных или законных прав, все, что препятствует

\footnotetext{
* Аспирантка Московской государственной юридической академии.
} 
правосудию или нарушает закон и все, что противоречит общественному устройству, и следовательно, недействительно и не должно исполняться. Вообще, под противоречием публичному порядку понимается противоречие основам государственного устройства, в том числе императивным нормам его законодательства, морали и общественной нравственности, на публичный порядок ссылаются, когда было нарушено право защиты одной из сторон. В принципе, любые императивные нормы нацелены на утверждение принципов, имеюших функциональное значение лля правовой системы их происхождения, и могут рассматриваться как составляющие публичный порядок соответствующего государства.

Следовательно, принимая решение о том, что данный спор не может быть предметом арбитражного разбирательства, суды в определенной мере затрагивают вопрос публичного порядка, ибо императивные нормы, в том числе и нормы, регулируюшие вопрос передачи отдельных категорий споров на арбитражное разбирательство, составляют часть публичного порядка государства. Многие правовые системы исключают подведомственность арбитражу споров о патентах, передаче ценных бумаг, о нарушении антимонопольного законодательства и другие.

По законодательству ряда стран недействительны оговорки, когда стороны подчиняют соглашение двум одновременно действуюшим правовым системам. Необходимо иметь в виду, что далеко не в каждой стране решение, вынесенное дружественным посредником, может быть исполнено. Тах, согласно договоренности, достигнутой между чехословацким истцом и турецким ответчиком, спор между ними был разрешен "дружественным посредником" на основании выбранного сторонами применимого права, но в исполнении этого решения в Турции было отказано, т.к. турецкое законодательство признает только решения, вынесенные на основании закона, несмотря на тот факт, что обе стороны согласились на разрешение спора дружественным посредником. ${ }^{2}$

Общим условием осушествления автономии воли является запрешение сторонам совершать злоумышленный обход закона. Выбор закона не должен иметь единственную цель - исключить императивные нормы, применение которых к договору в противном случае было бы обязательным.

Публичный порядок выполняет две функщии: защитную, зашишающую от применения иностранного закона, который нарушает принципы публичного или частного права, общего для цивилизованных наций и выражающего объективную мораль и справедливость; и активную, позволяющую правоприменительному органу применять нормы национального права независимо от того, что законом, свойственным договору, является право иного государства.

Говоря о публичном порядке, можно выделить три уровня:

а) национальный публичный правопорядок;

б) публичный правопорядок сообщества;

в) международный публичный правопорядок.

Каждый международный и национальный суд и арбитраж должен уважать и придерживаться принципов публичного порядка разрешения 
споров. Международный публичный порядок не ставит своей целью заменить право, которое окажется применимым, в конце концов, во многих случаях арбитраж не может точно определить применимое право. Определение "ordre public réellement international" (международный публичный порядок - фр.) не отличается ясностью. Можно сказать, что впервые публичный порядок был разделен на международный и внутренний $Ф$. Савиньи. Он вычленил, во-первых, императивные нормы, которые "вводятся только в интересах лиц, являющихся обладателями прав", а во-вторых, нормы, не только установленные в интересах отдельных лиц, но и покоящиеся на моральных основаниях или на "публичном интересе".

Современная правовая теория рассматривает две концепции публичного порядка: позитивную и негативную. Негативная концепция предполагает, что публичный порядок выражается через неприемлемые средства самого иностранного закона, в связи с чем его применение может нанести существенный ущерб правопорядку страны. Такая концепция закреплена в законодательстве Германии, Австрии, Венгрии, КНР, Российской Федерации. Опираясь на негативную концепцию, судебные органы, определив, что применение иностранного закона противоречит публичному порядку, применяют соответствуюшую правовую норму страны суда.

Согласно позитивной концепции публичный порядок составляет определенную совокупность материально-правовых норм государства, которые в силу своей когентности устраняют действие норм иностранного права. ${ }^{4}$ Позитивная конщепщия публичного порядка принята во Франции (ст. 6 ФГК). Эта концепция критикуется М.X. Бабаевым из-за ее противоречивости и несовместимости с практикой, поскольку, по его мнению, на практике реально применяется лишь негативная концепция. Тем не менее, представляется, что международный публичный порядок удобнее всего характеризовать именно с позиции позитивной концепции, ибо публичный порядок мирового сообщества составляют именно некие общие принщипы правопорядка. Нет сомнений, что такие принципы международного права, как уважение прав суверенных государств, основных свобод человека, являются основными нормами, составляющими международного публичного порядка.

В связи с этим хотелось бы упомянуть известное решение арбитража при Международной Торговой Палате № 1110 , вынесенное по спору между германской и британской фирмами. ${ }^{6}$ В 1950 году правительство Аргентины пригласило ряд корпораций для участия в тендере на увеличение мошности электрической сети в г. Буйнос-Айрес. Ответчик британская корпорация, имеющая офис в Аргентине, заплатила за участие в тендере 23 тысячи фунтов. В то время в стране правительственные договоры заключались не с теми, кто предложил наилучшие условия, а с теми, кто давал взятки соответствуюшим должностным лицам. Истец воспользовался услугами ответчика как посредника, хорошо знаюшего людей, связанных с данным вопросом. В результате истец "выиграл" тендер, истратив на "комиссионное вознаграждение" $10 \%$ от стоимости договора, тогда как мог заплатить 1-2\% от стоимости 
договора, если бы давал взятки самостоятельно. В 1955 году, в связи с изменением политического режима и отставкой прежних должностных лиц, истец стал персоной "non-grata" (неугодной - лат.). В 1957 г. британская корпорация опять участвовала в тендере, но более успешно, и в результате получила подряд на исполнение контракта на строительство электростанции в пригороде Буйнос-Айреса, стоимостью 4 миллиона фунтов стерлингов. Германская фирма потребовала 10\% от стоимости договора, поскольку считала, что успехи ответчика обусловлены ее усилиями за 6 лет до этого. Стороны обратились в Суд при Международной Торговой Палате в Париже. Судьей по этому делу был назначен Гунар Лагрегрен. Когда вопрос был исследован, арбитр поднял вопрос своей компетенции, поскольку, несмотря на то, что обе стороны дали свое согласие на рассмотрение дела в арбитраже, рассмотрение спора, основанного на правонарушении, противоречило бы основным принципам международного сообшества. В решении было сказано: “Невозможно отрицать существование обшего принципа права, признанного цивилизованными нациями, согласно которому договоры, серьезно нарушаюшие добрые нравы или международный публичный порядок, являются незаконными или, по крайней мере, не подлежашими принудительному исполнению, а поэтому не могут быть санкционированы судами или арбитрами."

Известный западный ученый профессор Голдман предложил, что международный публичный правопорядок в отношении международного коммерческого арбитража должен также включать в себя принцип соблюдения денежных обязательств. ${ }^{7}$ В международных отношениях, в странах, основанных на доктрине "соблюдения договора", ссылаясь на этот принцип, отказываются признавать национализацию или конфискацию собственности иностранным государством до тех пор, пока не выплачено справедливое и адекватное вознаграждение.

Говоря о публичном порядке сообществ, в первую очередь, хотелось бы затронуть проблемы публичного порядка в таких региональных сообществах как СЭВ и ЕС.

Публичный порядок СЭВ в области арбитражного разбирательства был установлен такими известными документами как Московская Конвенция о разрешении арбитражным путем гражданско-правовых споров, вытекающих из экономического и научно-технического сотрудничества между хозяйственными организациями стран-членов СЭВ 1972 года и Объединенные правила арбитража 1975 года странчленов СЭВ, содержащих унифицированные правовые нормы в области международного коммерческого арбитража. В соответствии с этими документами сам вопрос подведомственности и подсудности споров, вытекаюших из внешнеэкономических связей, являлся составной частью публичного порядка.

Публичный порядок СЭВ характеризовался обязательной юрисдикцией арбитражей при торгово-промышленных палатах государствучастников Конвенции по месту нахождения ответчика при рассмотрении гражданско-правовых споров, возникающих между “экономическими организациями в области экономического и научно-тех- 
нического сотрудничества в рамках Конвенции". Изменить это правило можно было только путем подчинения спора юрисдикции арбитражного суда при торгово-промышленной палате третьей страны, которая тоже является участником Конвенции. Решения таких арбитражных судов имели такую же юридическую силу как окончательные решения государственных судов этих государств. В исполнении решения могло быть отказано, если арбитражное решение вынесено судом, не имеющим соответствующей компетенции, предусмотренной Московской Конвенцией, при этом осталось неясным, что является приоритетным, если возникнет конфликт между публичным порядком СЭВ и национальным публичным порядком государства-участника. Статьи 85 и 86 Римского Договора, провозгласившего ЕЭС, учредили европейский публичный порядок, и национальные суды государств, теперь уже членов EC, применяя право ЕС, автоматически обращаются к публичному порядку Сообщества.

Изучение практики применения права Сообщества в Арбитраже при Международной Торговой палате показывает, что в, основном, эти споры, относятся к антимонопольному праву, и, в частности, к нарушению статей 85 и 86 Римского договора. Как следует из проведенного исследования, арбитры обращаются к антимонопольному законодательству ЕС при рассмотрении различных дел: антимонопольное законодательство ЕC применяется как арбитрами - гражданами EC, так и арбитрами из других государств, когда разбирательство имеет место на территории Сообщества и за его пределами, и даже в тех случаях, когда применимым правом является право государства, не являющегося членом ЕС. Тем не менее, кажется, что некоторые арбитры колеблются в отношении своих полномочий в этой области. Некоторые арбитры применяют антимонопольное законодательство без ограничений, а некоторые считают, что поскольку санкции за нарушение антимонопольного законодательства ЕС могут налагаться только судом, то такие споры неподведомственны арбитражу. Следует отметить, что нарушение публичного порядка ЕС, включающего, в частности, императивные нормы антимонопольного законодательства, по общему правилу препятствует рассмотрению дела в арбитраже, поскольку такие споры подведомственны исключительно судам государственным.

Все это видно из промежуточного решения по делу $\mathbf{N} 6106$ (1990) ${ }^{8}$, в котором юридическое лицо, созданное в соответствии с законодательством государства-члена EC, будучи ответчиком, возражало против подведомственности арбитражу спора между ним и истцом - юридическим лицом, находящимся под юрисдикцией государства, не являющегося членом ЕС. В споре, относящемся к соглашению о продаже акций третьей компании - производителю дисков, оспариваемое соглашение содержало оговорку об исключении конкуренции, в соответствии с которой продавец акций (ответчик) согласился не конкурировать с покупателем (истцом) или каким-либо из его дочерних предприятий в EC, США, Канаде и Мексике в течение пяти лет с даты заключения сделки по продаже акций. Арбитражное разбирательство было возбуждено покупателем, который, в частности, считал, что продавец не 
соблюдал оговорку об исключении конкуренции. Ответчик в своем отзыве указал, что, во-первых, данное дело не подведомственно арбитражу, и проскл арбитраж прекратить разбирательство, указав, что этот спор рассматривается в суде его страны.

Также ответчик заявил, что оговорка об исключении конкуренции противоречит положениям ст. 85 Римского договора. Арбитражный суд, состоящий из председательствуюшего - швейцарского арбитра и двух французских арбитров, обратился вначале к итальянскому праву, как к праву, применимому к договору, а затем к французскому, как к праву места суда. В соответствии как с итальянским, так и с французским правом арбитры вправе решить, что соглашение не противоречит статьям 85 и 86 Римского договора только в случаях, когда арбитры убеждены, что имеются нарушения, дело должно исключаться из подведомственности арбитражу. Следовательно, до момента принятия решения подведомственен ли спор о нарушении статей 85 и 86 Римского договора арбитражу, арбитры должны принять решение имело ли место такое нарушение. Изучив материалы дела, арбитражный суд пришел к выводу, что нарушений вышеназванных статей Римского договора не было, следовательно, спор может быть рассмотрен арбитражем, в противном случае, исходя из того, что за нарушение антимонопольного законодательства ЕС наказание может быть назначено только судом государственным, спор не был бы подведомственен арбитраху.

Во втором случае юридическое лицо ЕС (истец) возбудило дело о неподведомственности арбитражу одного из встречных исков ответчика - юридического лица не-ЕС ${ }^{9}$. Спор возник из лицензионного соглашения, в соответствии с которым истец выдал третьей стороне юридическому лицу не-ЕС (не вовлеченному в разбирательство) лицензию, а последняя в свою очередь выдала лицензию ответчику (юридическому лицу не-ЕС). Лицензионное соглашение, подписанное истцом, ответчиком и третьей стороной, предусматривало, что ответчик может использовать технологию истца только в скаңдинавских странах.

Истец хотел расторгнуть соглашение о выдаче последующей лицензии, поскольку ответчик не соблюдал свои договорные обязательства. В арбитражном разбирательстве истец требовал возмещение убытков, а также возврат документов, переданным им ответчику. Ответчик отверг иск и выдвинул несколько встречных исков, один из которых основывался на том, что истец нарушил положения статьи 86 Римского договора. Ответчик указал, что истец вместе с его материнской компанией пытались занять доминирующее положение на рынке путем исключения из него ответчика. В промежуточном решении арбитражный суд, состоявший из трех арбитров, не граждан ЕC, с местом арбитража в Лозанне, указали, в частности, что возражения против иска возникли из нарушения ст. 86 Римского договора и, следовательно, дело неподведомственно арбитражу. Следует отметить, что хотя дело рассматривалось не гражданами ЕС, правом страны места арбитража было швейцарское (Швейцария не является членом ЕС), но, тем не менее, они были вправе рассматривать спор, вытекающий из нарушений статей 85 и 86 Римского договора, принимая во внимание законодательство и практику как 
Швейцарии, так и ЕС. Основывая свое решение на положениях статьи 19 Закона Швейцарии о международном частном праве, арбитражный суд указывает, что следует также принимать во внимание некоторые друтие нормативные акты, кроме тех, которые применимы к сущности спора. Было отмечено, что по швейцарскому праву вопрос подведомственности арбитражу вопроса антимонопольного законодательства сильно отличается от этого вопроса по праву ЕС, в соответствии с которым споры о наличии, действительности или прекращении международных картельных соглашений подведомственны арбитражу без ограничений.

На национальном уровне публичный порядок основывается на принципах международного публичного порядка и публичного порядка региональных сообшеств.

В Германии в вопросах публичного порядка действующее законодательство разделяет внутренний и международный публичный порядок. Германское законодательство не содержит точного определения такой категории, которая исключала бы применение иностранного закона, если это противоречит добрым нравам и политике германского правительства (ст. 6 ЕВGB). Имперский суд Германии еще в 1918 г. дал свое толкование этой оговорки, констатировав, что к ней можно прибегать в тех случаях, когда различия между политическими и общественными взглядами, являюшиеся основаниями для иностранного и германского закона, настолько значительны, что применение иностранного закона может подорвать устои германской политической и экономической жизни. Германский суд, как правило, признает и приводит в исполнение арбитражное решение, основанное на lex mercatoria (торговом праве - лат.), по крайней мере, когда применение определено автономией воли.

В Англии по делу Saxby vs. Fubbon 1909 г., 2 К.В. 208 (С.А.) судья Вильям заявил, что “для отказа в применении какой-либо нормы иностранного закона необходимо, чтобы такое применение противоречило основам морали, которая считается преобладающей в этой стране, независимо от статутного права". Английские суды не признают договор, если признание явится враждебным актом по отношению к дружественному государству, т.е. нарушит соблюдение принципа международной вежливости, или в соответствии с таким договором на какую-либо сторону будет возложена обязанность исполнить обязательство, которое было бы противоправным в месте его исполнения. Такой подход является традиционным для английской судебной практики, считающей подобное применение естественным следствием теории о “праве, свойственном договору", т.е. с учетом правил валютного законодательства, ограничения процентов по обязательствам, антимонопольного законодательства, аннулирования определенных долгов.

Российское законодательство придерживается весьма ограниченной концепции публичного порядка в контексте международного частного права. Основы гражданского законодательства 1991 года предусматривают, что иностранное право не применяется в случаях, когда его применение противоречило бы основам российского правопорядка (статья 158 Основ гражданского законодательства 1991 года), т.е. требуется, 
чтобы само применение иностранного закона к конкретному случаю носило такой характер, который не может быть принят в рамках российского публичного порядка. В силу этого, при рассмотрении споров, вытекающих из внешнеторговых отношений, российскими государственными судами оговорка о публичном порядке применяется редко, в исключительных случаях. Статья 36 Закона РФ о международном коммерческом арбитраже предусматривает отказ в исполнении решения, принятого на основании lex mercatoria, по причине противоречия публичному порядку.

В Швейцарии, согласно закону о международном частном праве, отсылка к иностранному законодательству, сделанная в соответствии с указанным законом, включает все положения, которые по этому законодательству не могут быть исключены лишь по той причине, что такое положение носит публично-правовой характер (ст. 13).

Национальное законодательство всегда предусматривает право государственного суда по иску одной из сторон отменить решение арбитража или отказать в признании и приведении в исполнение иностранных арбитражных решений в случае, если решение противоречит публичному порядку государства или спор не может быть предметом разбирательства по законодательству этого государства. Такие основания установлены в статьях 34 и 36 Закона Российской Федерации “О международном коммерческом арбитраже”, в разделах 68 и 103 (3) Закона об арбитраже Великобритании 1996 года, и т.д. Необходимо иметь в виду, что, ссылаясь на публичный порядок, может быть отказано в исполнении решения в любом государстве. Практически все внутригосударственные акты, устанавливающие порядок признания и получения разрешения на приведение в исполнение иностранных арбитражных решений, содержат в качестве обязательного условия предписание, которое сводится $\mathrm{K}$ тому, чтобы иностранное арбитражное решение не содержало положений, противоречащих общественному порядку. Основной международно-правовой документ, регулирующий данный процесс - Конвенция 1958 года, предусматривает в качестве одного из оснований для отказа в признании и приведении в исполнение иностранного арбитражного решения противоречие признания и исполнения решения публичному порядку страны. Следует также иметь в виду, что ссылка на противоречие публичному порядку может быть использована на основании принципов международного частного права даже без специального указания в международных договорах.

Таким образом, ссылка на публичный порядок может быть использована национальными судами в двух случаях: в случае отмены решения арбитража и в процессе признания и приведения в исполнение иностранных арбитражных решений. Рассмотрим подробнее две эти ситуация.

Вступление решения арбитража в законную силу по законодательству государства, на территории которого оно было вынесено, является одной из предпосылок исполнения решения. Следовательно, передача на рассмотрение в арбитраж спора, который не может быть предметом арбитражного разбирательства, приведет к тому, что решение арбитража 
утратит свою исполнимость. В последнее время нормативные акты ряда государств, регулирующие арбитражное разбирательство, предусмотрели право сторон, не являющихся гражданами или юридическими лицами, подпадающими под юрисдикцию государства-места проведения арбитражного разбирательства, исключать юрисдикщию государственного суда по вопросу отмены вынесенного арбитражного решения. Такая тенденция вызвана стремлением полностью исключить международный коммерческий арбитраж из-под юрисдикции национального суда государства - места проведения разбирательства.

Согласно традиционной концепции, арбитраж осуществляется в соответствии с законодательством места его проведения, и, следовательно, будет ограничен публичным порядком государства - места разбирательства.

С другой стороны, в современной правовой науке сформировался такой подход, который отрицает наличие lex fori в международном коммерческом арбитраже, т.е. наличие правовой системы, имеющей приоритет для арбитров, как это имело место многие годы. Согласно этой теории необходимо учитывать тот факт, что право, выбранное сторонами, должно применяться в полном объеме, включая императивные нормы. В последнее время арбитры все чаще принимают во внимание иностранные императивные нормы как фактическое обстоятельство, подлежащее оценке в соответствии с применимым правом, либо непосредственно применяют такие нормы. В соответствии со статьей 9 Резолюции Института международного права 1991 года “Выбранное сторонами право подлежит применению без ущерба для императивных норм права места арбитража, которые должны применяться в данной ситуации, независимо от права, применимого к договору"10. Следовательно, современная концепция транснационального публичного порядка предусматривает исключительное и полное применение избранного права, а также широкий подход к применимому праву, выбранному сторонами, т.е. включение всех норм, в т.ч. и социальных и экономических, с целью обеспечить такое применение закона, которое было бы аналогично его применению в стране, где оно существует, т.е. с учетом фактов и общественных условий, существующих в стране.

Применимое право безусловно должно соотноситься с публичным порядком места, где, возможно, придется исполнять вынесенное решение. Вначале хотелось бы обратиться к известному делу между пакистанским банком (ответчик) и индийской компанией (истец). Банк выдал гарантию, стороны, исходя из принципа автономии воли сторон, подчинили выдачу банковской гарантии индийскому праву. По выпущенной гарантии банк не заплатил, поскольку между Пакистаном и Индией началась война, и вступил в силу чрезвычайный пакистанский закон, запретивший производить какие-либо платежи в Индию. Индийская компания, в соответствии с достигнутым ранее соглашением сторон, обратилась в арбитраж. Местом разбирательства была Швейцария, арбитром по данному делу был избран профессор Пьер Лялив. В результате изучения материалов дела арбитр, основываясь на том, что применимым правом при разрешении спора является индийское и, 
следовательно, пакистанский закон не отменил действительность гарантии, и, более того, поскольку противоправность исполнения не была установлена “законом, свойственным договору”, не было оснований для освобождения гаранта от его обязательств, вынес решение, согласно которому пакистанский банк обязан был совершить выплату в соответствии с гарантией, несмотря на то, что закон его собственного государства не разрешал этого. При вынесении решения арбитр не принял во внимание императивные нормы государства, где решение должно было исполняться. Стоит ли говорить о том, что возможность исполнения такого решения в Пакистане равна нулю. И, следовательно, данное решение утратило одну из важнейших черт решения - его исполнимость.

Вопрос о том, противоречит ли признание решения публичному порядку, должен быть исследован в отношении публичного порядка государств, в котором ходатайствуют о признании. Момент, когда должно быть проведено исследование вопроса о соответствии, должен совпадать с моментом представления ходатайства о признании. Однако, может иметь место и такая ситуация, когда вопрос о времени будет решаться в соответствии с национальным законодательством. Oпределение по вопросу о соответствии решения публичному порядку не должно быть обязательно окончательным (в смысле невозможности изменения этого критерия в какое-либо другое время).

С другой стороны, когда в национальный суд обращаются с просьбой о признании и приведении в исполнение иностранных арбитражных решений, в процессе рассмотрения такого ходатайства суд должен опять рассмотреть право сторон передать спор в арбитраж и возможность рассмотрения дела в арбитраже. Это правило не должно подлежать расширительному толкованию. Необходимо различать случаи, когда само решение противоречит публичному порядку (что не является законной причиной для отказа), и когда признание решения противоречит публичному порядку (что является законной причиной для отказа). В первом случае суд должен был бы пересматривать решение по существу, что запрещено, и делать это со ссылкой на публичный порядок государства исходного решения, т.е. делать то, что не имеют право делать суды другого государства. Статья 16 Римской Конвенции 1980 года гласит, что “отказ от применения права какой-либо страны, указанной в настоящей Конвенции, может последовать только, если такое применение явно не совместимо с публичным порядком места нахождения суда", т.е. не иностранный закон как таковой должен противоречить публичному порядку, а его конкретное применение в рассматриваемом споре. Кроме того, противоречие публичному порядку должно быть очевидным, а потому требующим специального обоснования в решении. Но, принимая во внимание все вышеизложенное, нельзя не отметить тот факт, что нельзя применить критерий соответствия публичному порядку, когда вопрос касается совместимости решения, вынесенного иностранным судом, и решения, вынесенного судом своего государства. 
1 Французская Республика: Конституция и законодательные акты. Под ред. B.A. Моршакова. - М., 1989.

2 ICC Awards, N 1525, Doc. N 410/1708, 15.02.69, discussed Supra, para 143. Site Julian D.M. Lew "Applicable Law in International Commercial Arbitration" N. Y. 1978. p. 570.

${ }^{3}$ Вольф $M$. Международное частное право. - М.,1984. - стр. 188.

${ }^{4}$ Международное частное право. Современные проблемы. Под ред. Богуславcкого М.M. - М., 1994. - стр. 464-465.

${ }^{5}$ Taм же. - cтp. 465

6 ICC Awards, N 1110, Doc N 410/1056, 15.01.63. - Site Julian D.M. Lew "Applicable Law in International Commercial Arbitration". N.Y. - 1978. p. 553.

7 Site Julian D.M. Lew "Applicable Law in International Commercial Arbitration". N.Y. 1978. p. 540.

8 International Commercial Arbitration in Europe. - ICC Publication N 537. Paris, 1994. - p. 51-52.

${ }^{9}$ International Commercial Arbitration in Europe, - ICC Publication N 537./ Case N 6858. (1991). - Paris, 1994. - p. 40-41.

${ }_{10}$ Мосс Джуудтта Кордеро. “Автономия воли в практике международного коммерческого арбитража". - М., 1996. - стр. 64.

Статья поступила в редакцию в апреле 2000 года.

\title{
МНОГОСТОРОННЕЕ СОГЛАШЕНИЕ ПО ИНВЕСТИЦИЯМ ПОЯВИТСЯ СНОВА
}

\author{
Кристиан де Б р и*
}

Под прикрытием конфликтов и кризисов, в бархатной тишине кабинетов вынашиваются планы между США, Европой и Всемирной торговой организацией (ВТО), нацеленные на устранение последних препятствий на пути свободной игры "рыночных сил" и на подчинение государств и народов безудержной экспансии транснациональных корпораций (ТНК). Учтя уроки поражения первой попытки навязать странам и народам Многостороннее соглашение по инвестициям (МСИ), деловые круги и технократы упорно стараются (и успешно) протолкнуть со второй попытки все тот же МСИ.

Еще при неостывшем трупе МСИ, положенном на полки Организации экономического сотрудничества и развития (ОЭСР), ультралиберальные доктора Джэкили (Фантастические персонажи из романа Стивенсона) под руководством отставного вице-президента Европейской комиссии тетчеристского динозавра Леона Бриттена пытаются

"Обозреватель газеты “Монд дипломатик” (Париж, Франция). 